\title{
CARTA-MANIFESTO AO COMPANHEIRO PAULO FREIRE: A CONJUNTURA NEOCONSERVADORA, AS (POUCAS) CONQUISTAS E A ESPERANÇA NA EDIFICAÇÃO DE UM NOVO MODO DE PRODUÇÃ̃O
}

\section{LETTER-MANIFESTO TO COMRADE PAULO FREIRE: THE NEO-CONSERVATIVE CONJUNCTURE, THE (FEW) ACHIEVEMENTS AND THE HOPE IN BUILDING A NEW MODE OF PRODUCTION}

Anderson dos Anjos Pereira Pena

Doutorando em Educação pela Universidade Federal do Ceará (UFC) Mestre em Cultura, Memória e Desenvolvimento Regional, Universidade do Estado da Bahia (UNEB) Professor Efetivo do Instituto Federal de Goiás (IFG), Campus Formosa. Fortaleza, Ceará - Brasil. anderson.pena@ifg.edu.br

Clarice Zientarski

Doutora em Educação pela Universidade Federal de Santa Maria (UFSM) Professora Adjunto da Universidade Federal do Ceará (UFC) Fortaleza, Ceará - Brasil. claricezientarski@yahoo.com.br

Resumo: Este documento tem o propósito de reconhecer o legado de Paulo Freire na educação, narrar um pouco mais acerca dos acontecimentos recentes para além das aparências fenomênicas com a finalidade de revelar o avanço imperialista das políticas neoliberais que têm como fito promover a destruição das forças produtivas (MONTORO, 2018), utilizando-se de táticas de guerra híbrida (KORYBKO, 2018). Esta é uma carta de reconhecimento e continuidade da luta travada por Freire; atualização sobre a conjuntura e renovação da esperança na transformação social cujo patrono da educação brasileira é um dos protagonistas históricos. Partimos do entendimento de que a educação não transforma imediatamente, mas pode mediar o desenvolvimento de um psiquismo enriquecido dos indivíduos. Propomos uma breve discussão acerca da relação entre o papel da educação, a superação do modo de produção capitalista e a edificação de uma sociedade que irreversivelmente possibilite a universalização do gênero humano, a igualdade e a liberdade. Compreendemos que o espaço aqui é abreviado, mas objetivamos que este texto estimule a ampliação do debate acerca da teoria pedagógica revolucionária.

Palavras-chave: esperança; neoconservadorismo; revolução.

Abstract: The purpose of this document is to recognize Paulo Freire's legacy in education, to tell a little more about recent events beyond phenomenal appearances in order to reveal the imperialist advance of neoliberal policies that aim to promote the destruction of productive forces (MONTORO, 2018), using hybrid warfare tactics (KORYBKO, 2018). This is a letter of recognition and continuity of Freire's struggle; update on the conjuncture and renewal of hope in social transformation whose patron of Brazilian education is one of the historical protagonists. We start from the understanding that education does not change immediately, but can mediate the development of an enriched psychism of individuals. We propose a brief discussion about the relationship between the role of education, the overcoming of the capitalist mode of production, and the building of a society that irreversibly enables the universalization of humankind, equality, and freedom. We understand that the space here is abbreviated, but we aim that this text stimulates the expansion of the debate about the revolutionary pedagogical theory.

Keywords: hope; neoconservatism; revolution.

Para citar - (ABNT NBR 6023:2018)

PENA, Anderson dos Anjos Pereira; ZIENTARSKI, Clarice. Carta-manifesto ao companheiro Paulo Freire: a conjuntura neoconservadora, as (poucas) conquistas e a esperança na edificação de um novo modo de produção. Eccos - Revista Científica, São Paulo, n. 58, p. 1-17, e15795, jul./set. 2021. Disponível em: https://doi.org/10.5585/eccos.n58.15795. 


\section{Introdução}

Estimado companheiro Paulo Freire:

Nós, estudiosos da pedagogia a serviço dos interesses das massas trabalhadoras, buscamos nos inspirar naqueles que lutam pelo povo, cujas referências práticas, você, querido companheiro, sempre nos auxilia na manutenção do estímulo para continuarmos firmes contra a barbárie e fortemente posicionados a favor da boniteza da vida. Por isso, escrevemos esta breve carta para registrar o nosso respeito à memória da sua luta pela educação que hoje se soma ao nosso combate e de tantos outros educadores revolucionários contra o contexto perverso que tem se agudizado cada vez mais desde que você "infelizmente se retirou do nosso convívio em 2 de maio de 1997" (SAVIANI, 2010).

Antes de tudo, queremos lhe contar que um movimento internacional ultraconservador se robusteceu por volta dos últimos anos do século XX e chegou ao Brasil do século XXI, demonstrando toda a sua raiva desvairada. Infelizmente, temos que lhe revelar isso, Paulo, mas, tendo em vista todo o seu esforço intelectual e prático, é triste notar que esse movimento tem mobilizado as massas - muitos oprimidos - contra os educadores e as escolas em nome do amordaçamento contra os direitos democráticos supostamente conquistados. A consequência é a violência direta e a possibilidade crescente de controle escamoteado do trabalho dos educadores e educadoras, além do patrulhamento ideológico capitaneado por igrejas totalitárias, burgueses conservadores e fascistas que atacam, processam judicialmente, mobilizam a mídia populista - alguns proprietários de igrejas também são proprietários de redes de telecomunicações, tais como sistemas de canais abertos e fechados de TV, rádios, portais de internet, entre outros. Eles também elaboram projetos de leis ${ }^{1}$ para cercear o direito de ensinar conteúdos científicos, filosóficos e artísticos nas escolas que entram em choque com a visão de mundo antropomorfizada, irracional e estranhada que tais conservadores querem perpetuar entre os oprimidos a fim de manter a opressão como você tão bem nos ensinou.

Nesse cenário, temos percebido uma progressiva escalada da "caça às bruxas" na sociedade brasileira. Vamos lhe relatar alguns tristes episódios começando pelo que entendemos ser a superfície do problema, a sua aparência fenomênica.

Alguém já deve ter lhe contado como Lula assumiu a Presidência da República, após ter sido eleito graças a um acordo de conciliação de classes que lhe assegurou o apoio de velhos membros das oligarquias, capitães das indústria e aval de alguns dos senhores do capital

\footnotetext{
"A bancada da "bíblia", majoritariamente composta por evangélicos do movimento neopentecostal que defendem a doutrina da "teologia da prosperidade" é numerosa e influente no Congresso Nacional, chegam a operar cultos dentro do próprio Congresso, sobre isso existe uma publicação que relata detalhes do projeto de poder desse grupo religioso no Brasil (DIP, 2018). 
bancário nacional e internacional. A conciliação parecia acenar para a reparação de algumas desigualdades históricas, mediante a elaboração e fortalecimento de diversas ações e programas sociais de combate à pobreza, à fome, de elevação da escolarização básica e superior das massas - incluindo aqui um programa que enviou muito filhos de pobres para o exterior, com bolsas de graduação e pós-graduação para cursos regulares e sanduíche -, de habitação, de combate ao desemprego e de inclusão dos pobres no mundo do consumo. Porém, internamente, os interesses antagônicos da capital boicotavam toda a estrutura e funcionalidade das reformas. Ao tempo em que o fluxo de socialização das riquezas do país fluía em progressão aritmética para as políticas sociais no âmbito do Estado, a progressão geométrica mantinha o caráter histórico do Estado burguês de grande comitê gerenciador dos interesses de toda a burguesia (MARX \& ENGELS, 1998). Quer dizer, a verdadeira expropriação e dilapidação dos esforços dos trabalhadores, que se expressam na riqueza da nação e que de certa forma ${ }^{2}$ aparecem no âmbito do Estado burguês na forma de tributos, são alvos de críticas violentas dos burgueses que se referem ao mau uso dos recursos destinados aos pobres, mas que na verdade escamoteiam o seu interesse voraz e puramente ganancioso de se apropriar, dos recursos para expansão da sua classe exclusivamente no âmbito desse Estado. Martins (2018, p. 129) explica que “o ataque desferido incide tanto sobre o 'salário direto' (pecúnia individual pelo trabalho realizado) quanto sobre o ‘salário indireto' (representado pelo retorno do trabalho sob a forma de serviços públicos)". Paulo, a situação já conhecida por você só tem piorado, pois a usurpação - legitimada pelas leis por eles mesmo aprovadas - dos fundos públicos e dos recursos do Estado em geral só revela o real caráter de excrecência parasitária do Estado burguês (MARX, 2012) que assim o é porque o modo de produção capitalista naturaliza a corrupção humana como apontou Vigotski:

Nas descrições clássicas do período inicial do capitalismo, Marx enfatiza frequentemente o tema da corrupção da personalidade humana que é provocada pelo crescimento da sociedade capitalista industrial. Em um dos extremos da sociedade, a divisão entre o trabalho intelectual e o físico, a separação entre a cidade e o campo, a exploração cruel do trabalho da criança e da mulher, pobreza e a impossibilidade de um desenvolvimento livre e completo do pleno potencial humano, e no outro extremo, ócio e luxo; disso tudo resulta não só que o tipo humano originalmente único torna-se diferenciado e fragmentado em vários tipos nas diversas classes sociais que, por sua vez, permanecem em agudo contraste umas às outras, mas também na corrupção e distorção da personalidade humana e sua sujeição a um desenvolvimento inadequado, unilateral em todas estas diferentes variantes do tipo humano. (VYGOTSKY, 2004, p. 2 e 3$)$.

\footnotetext{
${ }^{2}$ Não é nossa intenção levantar o debate econômico nesta carta. Podemos, sem embargo, fazê-lo em outro momento, até mesmo em áreas específicas, como na educação, por exemplo, apresentando todos os indicadores de expropriação que garantem o assalto do Estado pelas empresas, tanto em caráter objetivo quanto da usurpação da subjetividade das pessoas. Mas, para evitar a acusação de sermos evasivos, vai aqui uma breve lista (contemporânea e moderna) de estudos acerca dessa degenerescência corrupta que governa cada ação burguesa na condução dos seus interesses particulares ao se apropriar do Estado para torná-lo máximo para si e mínimo para os trabalhadores: Montoro (2016; 2018); Marx (2011); Korybko (2018); Lênin (1987).
} 
Durante os governos de Lula da Silva e Dilma Rousseff os pobres foram lembrados, mas os ricos usaram e abusaram do Estado. Só para que você possa ter uma ideia, Frigotto (2011) conta que entraram pelas portas das escolas os programas de educação financeira dos bancos públicos e privados, financiados pelo Ministério da Educação. Ele e outros intelectuais como Saviani (2008) denunciam também a instauração de um produtivismo tosco que cerceia os direitos dos professores no que tange à pesquisa e à produção científica e à relação da escola e da universidade com a sociedade. Querem transformar o professor em um aulista, rotulá-lo de improdutivo e preguiçoso, ao tempo em que se amplia a diversificação de disciplinas e conteúdos, quase sempre controlados e apostilados acerca do que esse professor deve ministrar para turmas lotadas ou através de teleaulas gravadas ou ao vivo. Lembramos-lhe de que tudo isso foi introduzido por um contemporâneo seu, aliado dos torturadores da ditadura civilempresarial-militar e que contribuiu para inserção das ideias privatistas e destruidoras na educação básica e superior públicas no Brasil. Referimo-nos a Valnir Chagas, braço direito do ex-ministro da Educação, coronel Jarbas Passarinho, e responsável pela edição das principais normas de interesse dos ditadores e empresários no Conselho Federal de Educação, que presidiu e por onde esteve por mais de uma década, ao mesmo tempo em que atuava no Ministério da Educação e influía na Universidade Federal do Ceará. Esse intelectual a serviço das elites e do militarismo implementou no nosso país a pedagogia tecnicista e, hoje, como outros integrantes da ditadura, é tratado como figura ilustre no Brasil e, especialmente por aqui, no Estado do Ceará, de onde escrevemos esta carta.

Para não nos estendermos muito, finalizamos essa denúncia acerca do assalto do Estado pelas elites - até aqui muito mais explicitado do ponto de vista ideológico, de empobrecimento e combate do acesso das massas aos direitos e política sociais - contando alguns brevíssimos episódios de como os homens mais ricos da nação ainda estão mais ricos a partir, justamente, do esgotamento das riquezas e da tomada do Estado brasileiro como um aparato da reprodução capitalista que garante a intermediação universal de mercadorias e a exploração da força de trabalho por meio da manutenção de uma "rede necessária de trabalho assalariado" (MASCARO, 2013, p. 18). Vamos começar pelos danos e revezes que atingem a classe trabalhadora.

\section{A classe trabalhadora brasileira: Por que mantê-la na condição de subalternidade?}

Os neoliberais dilapidaram, enfraqueceram e desarticularam as lutas populares durante os governos Lula e Dilma. Souza (2017, p. 60) advertiu sobre isso quando salientou que o pouco 
do que o Partido dos Trabalhadores - PT fez pela classe de baixa renda foi rechaçado pela sociedade conservadora, pois o verdadeiro objetivo das classes médias era "interromper o projeto de ascensão social dessas classes para que continuem sendo - exatamente como os escravos do passado - odiadas, superexploradas e desprezadas”. Desse modo, deram sequência ao seu projeto de poder, tramando um golpe articulado, que não brotou da classe dominante brasileira, pois seu viés é de fortalecimento internacional, reproduzindo no Brasil uma condição fortemente heterônoma que tem sido conveniente para aumento da dominação ampla sobre os pobresda América latina. Mas, com a anestesia do consumo e a ausência de um projeto popular democrático, a atuação dos neoliberais no governo de esquerda deu espaço para o surgimento de novas alianças que levou os sedentos gananciosos a paulatinamente abandonar o expresidente Lula e a se vincular a figuras tenebrosas que chegaram ao poder fazendo, de um lado, apologia a torturadores como Brilhante Ustra e, para nossa tristeza, por outro lado, requerendo o fim do legado de Paulo Freire nas escolas. Quem diria, não é mesmo, amigo Freire? Aliás, você já nos avisava sobre isso em uma conversa com seus companheiros Adriano Nogueira e Demerval Saviani:

[...] este momento neoliberal que estamos vivendo é uma fase do processo capitalista maior. É um momento decisivo, este. Não penso que ele tenha vindo pra dizer algo assim: olha, minha gente... vejamos se podemos humanizar o capitalismo, como já houve, antes, na História do processo capitalista de gerar/gerenciar a produção de riqueza. Nada disso. Este momento neoliberal tem um apetite enorme para excluir e terminar com grandes maiorias de Seres Humanos. Creio que devemos perguntar-nos: 'e por quê?" (SAVIANI, 2010, p. 2).

Acontece que a marcha gananciosa era o que estava em jogo e valeu a pena para os neoliberais até abandonar progressivamente a esquerda e apoiar o discurso fascista de Jair Bolsonaro e seus sequazes para colocá-los no poder em 2018. O que eles então passaram a ganhar e estão ganhando com isso? Sem colocar todos os episódios, mas levando em conta os mais importantes para a nossa temática, a sequência foi basicamente essa:

1. Em 2016 ocorreu o golpe articulado pela mídia, o judiciário, o parlamento e as forças políticas norte-americanas para derrubar o governo e que levaram ao impeachment da Presidenta Dilma Rousseff (SOUZA, 2017);

2. Uma das primeiras medidas para atacar a classe trabalhadora foi a decisão no Supremo Tribunal Federal $-\mathrm{STF}^{3}$ de que os dias sem trabalho por greve de servidores deveriam ser descontados, exceto se houvesse acordo de compensação. Essa decisão, acatada logo

\footnotetext{
${ }^{3}$ A decisão foi divulgada no próprio portal do STF: http://www.stf.jus.br/portal/cms/verNoticiaDetalhe.asp?idConteudo=328294. Acessado em 29 de setembro de 2019.
} 
após o golpe, cerceou o direito de greve do servidor público. Antes, para ser considerada ilegal, a greve deveria ser objeto de análise judicial, mas o STF assentiu que o próprio gestor público faça esse juízo e utilize o "chicote da fome”, ou seja, o corte de ponto, que significa desconto salarial, para impedir o servidor de fazer greve. Se observarmos, tratase aqui de uma estratégia para o que viria mais a frente: uma violenta sequência da agenda contrarreformista em detrimento da classe trabalhadora.

3. Iniciou-se, então, a intensificação de medidas que afetam tragicamente o salário direto e indireto das massas trabalhadoras no Governo do usurpador Michel Temer. A aprovação de tais medidas ocorreu acompanhada de táticas cada vez mais violentas de ataques contra os projetos populares, as esquerdas, os movimentos sociais dos trabalhadores, os sindicatos. As consequências imediatas que beneficiaram diretamente os cofres burgueses foram: a aprovação do congelamento dos gastos públicos com políticas sociais, com a educação como um dos setores mais afetados pela Emenda Constitucional $n^{\circ} 95$, que já está em vigor desde o ano de 2016 e perdurará, se nada acontecer, por vinte anos. A EC 95 determina o contingenciado dos gastos governamentais e atividades essenciais, como educação e saúde, para utilizar os recursos a serviço da cobertura de dívida pública, o que significa a remuneração dos juros dos rentistas, investidores privados. Ainda durante o governo de Temer - que preparou as bases com perfeição para que um presidente ainda pior pudesse assumir, como se tudo estivesse muito bem articulado. Todas as evidências atuais trazem à tona fatos que essa costura era tecida no âmbito da dissimulada Operação Lava $\mathrm{Jato}^{4}$ - os direitos trabalhistas foram totalmente descaracterizados. O parlamento aprovou a terceirização irrestrita, sancionada pelo presidente em 2016, e assentida pelo STF no ano de 2018, que permitiu um verdadeiro "libera geral" nas contratações de empresas terceirizadas. Antes proibida, a atividade fim passou a ser permitida com a promulgação da nova Lei $n^{\circ} 13.429 / 17$ e, com isso, as portas se abriram de vez para a exploração máxima e sonegação dos direitos dos trabalhadores que, paralelamente, viram seus direitos ainda mais destruídos com a desastrosa reforma trabalhista do ano de 2017. A Lei $\mathrm{n}^{\circ} 13.467$ estabeleceu a reforma trabalhista e passou a

\footnotetext{
${ }^{4}$ Sobre este fato, Freire, algo inusitado aconteceu no ano de 2019. O site The Intercept Brasil divulgou uma série de reportagens acerca do vazamento de conversas - ofertadas por fonte anônima - entre procuradores da suposta maior operação judicial do país que foi politicamente edificada pelas potências hegemônicas internacionais e elites subalternas locais em parceria com agências de interesse político, econômico, jurídico e policial europeias e, especialmente, estadunidenses a fim de neutralizar/destruir o papel político e a atuação das esquerdas, sindicatos e movimentos sociais e facilitar todo o assalto do Estado e destruição das forças produtivas. Nessa marcha jurídico-política local, que facilitou a chegada de Jair Bolsonaro e do grupo ultraconservador de direita ao poder, esteve à frente o responsável por táticas fascistas, populistas e criminosas no interior do judiciário, o ex-ministro da Justiça, Sergio Moro, que foi premiado com o cargo por, entre outras coisas, chefiar a força-tarefa de um processo investigatório, como juiz, no qual se tornou o chefe direto dos promotores e delegados da operação, manipulou e ocultou provas, utilizou a mídia ao seu bel-prazer, fez de delações premiadas verdadeiras loterias, com o fito de se promover através da prisão do ex-presidente Lula, que foi um encarcerado político e também de outros petistas que foram alvo da sua fúria antiesquerdista, punitivista e odiosa. Todos os fatos estão disponíveis no site e são compartilhados também com outros jornais nacionais e internacionais que resolveram divulgar as notícias do The Intercept Brasil (o próprio site os indica): www.theintercept.com/brasil.
} 
valer no dia 11 de novembro de 2017, cento e vinte dias após a sua publicação no Diário Oficial da União. Tal reforma destruiu direitos significativos para permitir, por exemplo, que gestante e lactantes possam realizar trabalhos insalubres (medida posteriormente derrubada pela STF); que a homologação da rescisão do contrato de trabalho possa ser realizada na própria empresa, desobrigando a sua realização no âmbito sindical; excluiu do tempo referente ao cômputo que perfaz a jornada de trabalho referente ao que o trabalhador gasta, dentro da empresa, com higiene pessoal, deslocamento e troca de uniforme; as horas in itineranti, que são as que o trabalhador utilizava para se deslocar até a empresa também foram oficialmente abolidas por essa Lei; agora, admite-se formas de contratação alternativas, anteriormente consideradas ilegais, mas regulamentadas pela Lei $\mathrm{n}^{\circ} 13.467$, como o trabalho intermitente, no qual o trabalhador é remunerado pelo período de trabalho e o pagamento de férias e o décimo terceiro salário proporcional e o desconto do imposto sindical passaram a ser facultativos. Foi uma forma da classe dominante enfraquecer ainda mais os sindicatos, retirando-lhe recursos, mas sem abolir o imposto sindical e mantendo a estrutura sindicalista atrelada ao Estado, porém impondo limitações ainda maiores à base da organização dos trabalhadores a fim de desmobilizálos.

4. Passou-se a viver um processo de direitização que envolve a sociedade e a política por meio da imposição ideológica, da prática e cerceamento à liberdade de expressão. Isso pode ser evidenciado com a Lei 12.850/2013, conhecida como Lei Antiterror, que foi aprovada pelo Congresso Nacional que abriu espaço para que movimentos sociais fossem criminalizados ao autorizar que agentes de segurança pública e magistrados interpretassem o que era ou não um ato de terrorismo. Com efeito, uma experiência denota que essa Lei foi dirigida contra quatro integrantes do Movimento dos Trabalhadores Rurais Sem-Terra (MST) pela justiça do estado de Goiás que os prendeu preventivamente sob a acusação de integrarem organização criminosa ${ }^{5}$ e tendo como fulcro esse instrumento legal aplicado deliberadamente contra uma entidade organizativa das massas trabalhadoras do país. Dois outros episódios são muito importantes para avaliarmos algumas das consequências desse processo de direitização no Brasil: o assassinato da vereadora do Partido Socialismo e Liberdade - PSOL, Marielle Franco, que teve sua vida brutalmente retirada junto ao motorista Anderson Gomes em uma emboscada, no Rio de Janeiro; e a condenação e prisão política do nosso ex-presidente,

${ }^{5}$ Atitude amplamente divulgada pelos veículos de mídia, a exemplo do jornal O Estado de S. Paulo. Disponível em: 
Lula. A vereadora, socióloga e intelectual orgânica das massas populares, de apenas 38 anos de idade, foi friamente executada na capital fluminense junto a Anderson Gomes, no dia 14 de março e 2018. Marielle foi presidente da Comissão da Mulher na Câmara do Rio e integrava a comissão que investigava os abusos das Forças Armadas e da polícia durante a intervenção militar determinada pelo presidente Michel Temer na segurança pública do Estado do Rio de Janeiro. No caso do ex-presidente Lula, notou-se uma atuação ilegal de agentes do Ministério Público, sob o comando do ex-juiz federal Sérgio Moro, a fim de acusá-lo a todo custo. O resultado dessa estratégia escusa foi a retirada de Lula da campanha eleitoral de 2018 e ações de vazamento feitas pelo juiz que beneficiaram a eleição de Jair Bolsonaro, a exemplo do vazamento de conteúdos da delação premiada feita pelo ex-ministro petista, Antonio Palocci que supostamente implicavam o ex-presidente Lula, às vésperas do primeiro turno das eleições presidenciais. Uma vez eleito, Jair Bolsonaro brindou Sérgio Moro com o cargo de ministro da Justiça e Segurança Pública. Com pouco mais de um ano de atuação no Ministério, Sérgio Moro deixou o governo denunciando possíveis crimes cometidos pelo presidente da República. Em 2021, os fortes indícios de atuação política do ex-juiz contra Lula foram julgados pelo STF que o considerou parcial e suspendeu todos os atos praticados por Moro na ação que o fez manter Lula preso por 580 dias.

5. Na atualidade, o País é dirigido por um governo cujos integrantes principais, a começar pelo chefe do executivo, são apologetas da tortura, defensores do militarismo, praguejadores anticomunistas, criminalizadores dos movimentos sociais, estimuladores do ódio e da violência direta - com afirmações de incentivo direto e explicitamente proferidas em discursos de campanha e atuais do presidente em que afirma seu desejo de eliminar a "petralhada" ou pede para fuzilar os esquerdistas. Como mencionamos em um primeiro momento, o cenário político neoliberal se manifesta em negações imediatas das condições básicas que possibilitam a prometida cidadania, proclamada no formalista discurso contratual da igualdade, liberdade e fraternidade. Na realidade, se manifesta na precarização e destruição do contrato social e tem jogado muitos trabalhadores em total condição de miséria e desigualdade. Daí se explica e se justifica todo o ódio burguês aos que nada têm expresso nos ataques crescentes e práticas jurídico-políticas de criminalização dos movimentos sociais. A meta que tem sido atingida é ganhar a adesão da grande massa, incluindo os favelados oprimidos urbanos, capitaneados pela mídia, bispos, apóstolos e pastores de alguns segmentos neopentecostais que de suas igrejas pregam a teologia da prosperidade e o ódio implacável aos trabalhadores que têm o direito 
à terra negado e, mais do que isso, a uma vida roubada em nome da manutenção da vida luxuosa dos privilegiados donos do agronegócio e dos latifundiários tradicionais.

A consequência de todo esse discurso de ódio, companheiro Freire, que não se espalha por redes sociais, mídias, igrejas e nos locais onde os trabalhadores precisam vender sua força de trabalho ${ }^{6}$, pode ser verificada, por exemplo, no relatório de 2018 da Comissão Pastoral da Terra - CPT (2018).

Entre 1985 e 2018, 1.938 pessoas foram executadas em conflitos pela terra, água e trabalho no Brasil e 1.789 desses casos (92\%) continuam sem qualquer responsável julgado; entre 2017 e 2018, 95 pessoas foram assassinadas em conflitos pela terra de acordo com o estudo realizado pela CPT.

O número de conflitos no campo no Brasil registrados pela CPT cresceu 4\% em 2018, chegando a 1.489 . O número de pessoas envolvidas aumentou $35,6 \%$ e foi para 960.630 . O total de mulheres envolvidas em casos de violência chegou a 482, o maior número em 10 anos.

Houve também o aumento absurdo do total de famílias expulsas de suas terras, geralmente de forma violenta: 2.305, crescimento de 59\% em relação a 2017. A maior parte concentra-se na região Norte (36,3\% do total), seguida de perto pelo Sudeste $(35,6 \%)$.

Deixe-nos contar um pouco mais para você também acerca de alguns dados registrados sobre a realidade empírica do campo e da cidade daqui do Estado do Ceará:

- A CPT (2018) apontou que no Estado do Ceará, os conflitos em busca do direito a terras aumentaram em $87,5 \%$ entre 2017 e 2018 ;

- Caucaia, Maracanaú e Pacatuba aparecem como os municípios onde mais foram registrados conflitos;

- Ocorreram 7 chacinas que deixaram 48 mortos no Estado do Ceará no ano de 2018;

Em 2018, foram registrados oficialmente pelos órgãos de governo no Estado do Ceará mais de 4.460 homicídios, se somados aos 5.113 de 2017, esse número chega a quase 10 mil ocorrências, a maioria de jovens de 15 a 29 anos, conforme revela o portal de notícias G1.

Esse cenário atual não tira da lembrança o seu repúdio ao assassinato do índio pataxó, Galdino Jesus dos Santos, uma das últimas palavras escritas por você no dia 21 de abril de 1997 ,

\footnotetext{
6 ““Você está preparado para sair da Havan? Você está preparado para ganhar a conta da Havan? Você que sonha em ser líder, gerente, e crescer com a Havan, você já imaginou que tudo isso pode acabar no dia 7 de outubro?', diz o empresário apoiador de Bolsonaro". Este é um pequeno trecho da reportagem na Revista Fórum que mostrou como proprietário da rede de lojas Havan coagia seus milhares funcionários a apoiar o projeto de poder da extrema direita nas eleições de 2018. Para ler a reportagem completa é possível consultar o site da revista: https://revistaforum.com.br/direitos/em-video-dono-da-havan-coage-funcionarios-avotarem-em-bolsonaro/. Acesso em: 30 set. 2019.
} 
e queremos destacar aqui, um trecho deste documento histórico tão importante deixado por você, companheiro:

\begin{abstract}
Que coisa estranha, brincar de matar índio, de matar gente. Fico a pensar aqui, mergulhado no abismo de uma profunda perplexidade, espantado diante da perversidade intolerável desses moços desgentificando-se, no ambiente em que decresceram em lugar de crescer. Penso em suas casas, em sua classe social, em sua vizinhança, em sua escola. Penso, entre outras coisas mais, no testemunho que thes deram de pensar e de como pensar. A posição do pobre, do mendigo, do negro, da mulher, do camponês, do operário, do índio neste pensar. Penso na mentalidade materialista da posse das coisas, no descaso pela decência, na fixação do prazer, no desrespeito pelas coisas do espírito, consideradas de menor ou de nenhuma valia. Adivinho o reforço deste pensar em muitos momentos da experiência escolar em que o índio continua minimizado. Registro o todopoderosismo de suas liberdades, isentas de qualquer limite, liberdades virando licenciosidade, zombando de tudo e de todos. Imagino a importância do viver fácil na escala de seus valores em que a ética maior, a que rege as relações no cotidiano das pessoas terá inexistido quase por completo. Em seu lugar, a ética do mercado, do lucro. As pessoas valendo pelo que ganham em dinheiro por mês. $\mathrm{O}$ acatamento ao outro, o respeito ao mais fraco, a reverência à vida não só humana, mas vegetal e animal, o cuidado com as coisas, o gosto da boniteza, a valoração dos sentimentos, tudo isso reduzido a nenhuma ou quase nenhuma importância (FREIRE, 2000, p. 31).
\end{abstract}

As formas de matar índios, negros, pobres, sem-terra, sem teto, mulheres, gays, lésbicas, travestis, defensores dos direitos humanos e educadores têm ficado cada vez mais sofisticadas, como você pode notar, e agora se planeja a entrega para morte ou desalento de tantos futuros idosos, viúvos e viúvas e pessoas com deficiência com a aprovação da reforma da Previdência que possui semelhanças com a que foi realizada no Chile, que, segundo do jornal Gazeta do $\mathrm{Povo}^{7}$, elevou os índices de suicídio dos chilenos, cujas aposentadorias reduziram os níveis de vida da população. O aumento do valor e do tempo de contribuição, a redução de valores das pensões (que ficaram abaixo do que quando estavam na ativa), o fato de que as viúvas e viúvos não sejam contemplados com pensões integrais determinou a destruição de direitos e afronta à dignidade humana, tornando-se cada vez mais forte no Brasil. A desgentificação ou destruição das forças produtivas aumenta e fortalece o todopoderissimo, que é o imperialismo na sua forma mais agressiva, de escancarada financeirização, especulação e aumento do mais-valor (MONTORO, 2018).

Porém, para muitos oprimidos, as possibilidades de resistir a tal situação vulnerabilizase pela aplicação ostensiva de disseminação da visão de mundo dos opressores. Atualmente ao invés de "cassetete da polícia, temos aqui a manipulação midiática das necessidades de autolegitimação da classe média transmutada sem defesa da moralidade estreita da suposta corrupção patrimonialista” (SOUZA, 2017, p. 119). Mézsáros (2004, p. 479), ao tratar do poder

\footnotetext{
${ }^{7}$ Ver: https://www.gazetadopovo.com.br/vozes/a-protagonista/aposentadorianochile/. Acessado em 30 de setembro de 2019
} 
da ideologia, sublinha que: "o impacto maciço da ideologia dominante na vida social como um todo só pode ser apreendido em termos da profunda afinidade estrutural existente entre as mistificações e as inversões práticas, por um lado, e suas conceituações intelectuais em outro". Com efeito, entendemos que para superar as mistificações e inversões práticas da atualidade, bem como suas conceituações intelectuais, é preciso compreender que as estratégias diretas para convencer as massas vêm ocorrendo conforme a orientação internacional da grande burguesia de tornar a "guerra direta" desnecessária. Afinal, um novo modelo de guerra é totalmente viabilizado sem um processo caro, sanguinário e ruim para a imagem imediata dos burgueses, ajudando-os a legitimar sua natureza corrupta e sua saga assassina entre os dominados, com amplo consenso. Através da "guerra indireta", uma espécie de hibridismo estratégico inspirado em tradições milenaristas militares prospectavam a vitória a partir do ataque ao inimigo abrindo mão do confronto direito. Na atualidade, como descreve Korybko, essa "guerra indireta" tem se materializado por meio da atuação das "quintas-colunas":

[...] compostas menos por agentes secretos e sabotadores ocultos e mais por protagonistas desvinculados do Estado que comportam-se publicamente como civis. As mídias sociais e tecnologias afins substituirão as munições de precisão guiadas como armas de "ataque cirúrgico" da parte agressora, e as salas de bate-papo online e páginas no Facebook se tornarão o novo "covil dos militantes". Em vez de confrontar diretamente os alvos em seu próprio território, conflitos por procuração serão promovidos na vizinhança dos alvos para desestabilizar sua periferia. As tradicionais ocupações militares podem dar lugar a golpes e operações indiretas para troca de regime, que tem um melhor custo-benefício e são menos sensíveis do ponto de vista político (KORYBKO, 2018, p. 12).

Esse modelo de guerra indireta tem sido bastante eficaz no Brasil. Por meio de disseminação de mentiras e do recrudescimento do obscurantismo ataca-se a ciência, a noção de verdade e de conhecimento e a barbárie é naturalizada. Os alvos dessa guerra, como analisa Newton Duarte (2020), se multiplicam dentro e fora da escola e intencionam a eliminação do pensamento de esquerda, acusando todo e qualquer pensamento crítico de " esquerdismo". Com o claro objetivo antidemocrático de eliminar o pensamento de esquerda, milícias digitais e hordas neofascistas procuram vetar "discussões sobre as desigualdades sociais, a destruição ambiental gerada pela produção capitalista, as crises econômicas, a exploração do trabalho, a dominação militar de países e regiões pelas grandes potencias imperialistas, as muitas formas de preconceito e de relações sociais opressivas etc.” (DUARTE, 2021, p. 32 e 33).

Os ataques obscurantistas se voltam contra a educação escolar e os professores. Levantam bandeiras ideológicas que pregam a escola sem partido, o homeschooling (ensino domiciliar) e a militarização das escolas públicas. Para Duarte, esses ataques obscurantistas à educação escolar não possuem nada de neutro, embora este seja o argumento por eles utilizado. 
$\mathrm{Na}$ verdade, o que se esconde por trás das suas falas e atitudes são intenções "de fazer da educação um processo de imensa doutrinação obscurantista neoliberal" e de "impedir que o sistema escolar público avance em direção à democratização do acesso à cultura científica, artística e filosófica [...]” (DUARTE, 2021, p. 34).

Isso posto, integramos às suas orientações, a que Herbert Marcuse também nos fornece, registrada no "prólogo" da obra $O 18$ de Brumário de Luís Bonaparte:

\begin{abstract}
Nos dias atuais, em que a própria irracionalidade se converteu em razão, seu único modo de ser é a razão da dominação. Assim, ela continua sendo a razão da exploração e da repressão inclusive quando os dominados colaboram com ela. E, em toda parte, ainda há aqueles que protestam, que se rebelam, que combatem. Até mesmo na sociedade superabundância eles estão aí: os jovens, que ainda não desaprenderam a ver, a ouvir e a pensar, que ainda não abdicaram, e aqueles que ainda são as vítimas da superabundância e que dolorosamente estão apenas começando a aprender a ver, ouvir e pensar (MARCUSE apud MARX, 2011, p. 15 e 16, grifos nossos).
\end{abstract}

Com efeito, entendemos que a permanente luta que mede forças entre poderosos e fracos, opressores e oprimidos se confirma na história dos indivíduos concretamente constituída por uma inalterável luta de classes que precisa ser superada pela constituição de um novo modo de produção que destrua a raiz da origem de tais contradições que movimentam os antagonismos: as próprias classes sociais. Como essa prática se configura na educação brasileira é o que vamos pensar juntos na sequência em que discutimos os estragos provocados na formação da classe trabalhadora.

\title{
A educação da classe trabalhadora brasileira como alvo da elite dominante
}

No início do século XXI, Shiroma, Moraes e Evangelista em Política Educacional (2005,) realizaram um esforço científico para denunciar o papel dos organismos internacionais e a realização de conferências - sempre com o apoio do Banco Mundial, do Fundo Monetário Internacional e de agências financeiras com sede nos países capitalistas mais ricos - a fim de pautar os seus interesses na educação dos pobres da América Latina. O problema identificado pelas autoras apontou que esses organismos e as empresas ricas que os sustentam e a eles se associam de fato desejavam que os pobres estivessem bem distantes do conhecimento. Porém, essa constatação se completa com situações ainda mais recentes que nos alertam que não se tratava, desde o início, de um simples apartar os pobres do saber escolar, mas de uma forma de ganhar muito dinheiro com isso. O que a classe dominante desejava com essas preocupações educacionais tem se revelado agora com as diversas formas de privatização da educação escolar. Destacamos o papel das corporações na fundação de conglomerados de empresas bilionárias, 
pertencentes aos homens mais ricos do país e do mundo que quando não lucram diretamente através das suas organizações sociais, o fazem através de outras empresas que paralelamente se privilegiam da atuação de organizações sociais para deixar o mercado aberto para eles mesmos serem contratados. Dessa forma, executam programas de formação de professores, vendem materiais didáticos e tecnologias para as escolas públicas, realizam a gestão direta das escolas sob o argumento da ineficiência da coisa pública, entre outras práticas privatizantes que maximizam os lucros e aumentam o controle ideológico dos dominadores sobre os dominados nas escolas que gradativamente passam a ser por eles controladas.

Trata-se dos sistemas privados de ensino que são vendidos aos municípios e da atuação de grupos empresariais na educação e sua inserção nas redes públicas de ensino (ADRIÃO, 2013). Mais precisamente, presencia-se a privatização de processos como a definição dos currículos escolares do sistema público; a elaboração e aplicação de avaliações sistemáticas desses currículos; os procedimentos de formação a serviço dos educadores (professores e gestores); a qualificação de assessorias técnicas e jurídicas de esferas governamentais, incluindo formas de supervisão de ensino desenvolvidas nas escolas e "se verifica nos mercados educacionais brasileiros a presença das corporações" através dos “"Sistemas Privados de Ensino' e, concomitantemente, pela presença dessas corporações no Programa Nacional do Livro Didático (PNLD)" (ADRIÃO, 2017, p. 130).

Em termos gerais, foi assim que um grande acordo nacional foi realizado entre o empresariado e seus prepostos em defesa dos seus interesses na política. Esse grupo destruiu a educação pública e facilitou a sua entrega à iniciativa privada, abrindo o mercado para as empresas mais ricas, que têm a frente os autoproclamados filantropos da atualidade, a partir da Emenda Constitucional $n^{\circ} 95$ que está entre as ações privatistas para os próximos vinte anos. Paulo, como você pode perceber, de 2016 para cá, a população de baixa renda está cada vez mais longe do ensino superior. Isso aconteceu a partir de medidas como a aprovação da Lei ${ }^{\circ}$. 13.415, de 16 de fevereiro de 2017, que altera o Art. 36, da Lei ${ }^{\circ}$ 9.394, de 20 de dezembro de 1996 e impôs uma reforma ao ensino médio similar ao que fez o Valnir Chagas que garantiu o distanciamento da universidade para os pobres e facilitou o caminho do tecnicismo sob a falsa promessa de inclusão no mercado de trabalho.

Como novidades desse novo ensino médio, vem um discurso sedutor de que os jovens podem escolher itinerários formativos vinculados à Base Nacional Comum Curricular - BNCC. Isso significa que os filhos das massas trabalhadoras são induzidos a uma escolha espontaneísta e imediatista vinculada às suas necessidades de inserção no mercado de trabalho, enquanto os filhos das camadas médias e das elites continuam a optar pelas carreiras de maior prestígio que 
se vinculam ao oportunismo e à usurpação privilegiada da sociedade pelo Estado burguês. Com efeito, reitera-se o neotecnicismo (SAVIANI, 2008) na educação. Nunca o projeto defendido pelo Valnir Chagas foi tão forte e, deixemos claro, sem o uso explícito da força. Um "detalhe" é que se admitirá até mesmo a contratação de professores sem formação em nível de graduação, aceitando-se, no caso, o notório saber, cuja legislação atual permite a formação de determinados componentes curriculares do novo ensino médio. Cabe imaginar como será a atuação do notório saber nas escolas de elite do país!

Para arruinar ainda mais as possiblidades de elevação intelectual das massas, a ofensiva do capital vem recheada de uma proposta em defesa de uma suposta neutralidade científica. Os defensores dessas ideias solicitam que estudantes gravem aulas dos professores considerados doutrinadores marxistas, esquerdistas e que querem impor uma ideologia de gênero. A situação é tão grave, Paulo Freire, que tramitam por diversas casas legislativas do país e no Congresso Nacional projetos de Lei denominados "Escola sem partido" ". Cabe aqui um registro do que consideramos ser uma explicação filosófica do companheiro Saviani sobre a neutralidade científica e que pode auxiliar os educadores em uma resposta a essa superficialidade e um estímulo à barbárie e ao desconhecimento perpetrados pelos apologetas dessa efeméride com a qual nos desejam amordaçar.

Importa, pois, compreender que a questão da neutralidade (ou não neutralidade) é uma questão ideológica, isto é, diz respeito ao caráter interessado ou não do conhecimento, enquanto a objetividade (ou não objetividade) é uma questão gnosiológica, isto é, diz respeito à correspondência ou não do conhecimento com a realidade à qual se refere. Por aí se pode perceber que não existe conhecimento desinteressado; portanto, a neutralidade é impossível. Entretanto, o caráter sempre interessado do conhecimento não significa a impossibilidade da objetividade. Com efeito, se existem interesses que se opõem à objetividade do conhecimento, há interesses que não só não se opõem como exigem essa objetividade. É nesse sentido que podemos afirmar que, na atual etapa histórica, os interesses da burguesia tendem cada vez mais a se opor à objetividade do conhecimento, encontrando cada vez mais dificuldades de se justificar racionalmente, ao passo que os interesses proletários exigem a objetividade e tendem cada vez mais a se expressar objetiva e racionalmente. É fácil compreender isso uma vez que a burguesia, beneficiária das condições de exploração, não tem interesse algum em desvendá-las, ao passo que o proletariado que sofre a exploração tem todo interesse em desvendar os mecanismos dessa situação, que é objetiva (SAVIANI, 2013, p. 49 e 50).

O conhecimento da realidade relaciona-se à perspectiva ontológica de apropriação objetiva do mundo pelo pensamento humano, e isso jamais poderá ser neutro, pois trata-se de um processo de desantropomorfização complexo, sistemático e gradual e não pode ocorrer

\footnotetext{
${ }^{8}$ Ver, por exemplo, BRASIL. Projeto de lei n ${ }^{\circ} 867$, de 2015. O texto inclui, entre as diretrizes e bases da educação nacional, o "programa Escola sem Partido". Câmara dos deputados. Brasília. DF, 23 de maio de2015. Disponível em

https://www.camara.leg.br/proposicoesWeb/prop_mostrarintegra;jsessionid=375C72096AFD87644868A98ED8436064.proposicoesWebExterno2? codteor=131 7168\&filename=Avulso+-PL+867/2015. Acesso em: 29 set. 2019.
} 
espontaneamente, requer mediação e precisa se efetivar sob o risco da humanidade não se efetivar em cada ser singular, como nos orienta a psicologia marxista da Escola de Vigotski (VIGOTSKI, 2009; LEONTIEV, 1978). A questão que está em jogo na defesa da neutralidade é, portanto, amigo Freire, uma questão ideológica de um grupo dominante que se coloca contra a história a fim de reivindicar para si as conquistas mais desenvolvidas da humanidade exclusivamente para seu usufruto particular e para a criação de um modelo de organização social, como você nos ensinou, baseado no valor de troca, no mercado, na venda e não nas pessoas, na desgentificação.

Entendemos ser de suma importância que a classe trabalhadora torne-se classe para si, organizando-se de forma revolucionária para implantar a verdadeira democracia através de um processo revolucionário permanente (TROTSKY, 2007), posto que a democracia burguesa é uma farsa e o Estado burguês deve ser destruído (LÊNIN, 1987; MARX, 2012). Isso para que a humanidade possa brotar neste planeta e enfim possamos pensar em viver a boniteza da vida, longe da malvadez da classe que nos oprime e esmaga.

\section{Considerações finais: para manter viva a esperança na revolução}

Por fim, companheiro, entendemos que a referência fundamental da psicologia a ser seguida no processo de mediação pelos professores na educação escolar considera a situação de síntese em que supostamente estão, e destaca relevância do seu papel na mediação do desenvolvimento das funções psíquicas dos alunos - que estão em condição sincrética, portanto, em processo de humanização. Em outras palavras, “o professor 'empresta' ao aluno aquilo que já conquistou - quer em termos dos processos funcionais superiores, quer em termos dos conteúdos escolares a serem transmitidos” (MARTINS, 2013, p. 295).

Diante do que foi exposto, entende-se que a luta pela educação escolar pode ser formulada tendo como propósito a elevação intelectual das massas que passa pela "sólida formação de professores, que os instrumentalizem teórica e metodologicamente para a assunção da complexa tarefa representada nos processos de ensino e aprendizagem" (MARTINS, 2013, p. 288) e, também, conforme nos orienta Lombardi (2013, p. 13, grifos do autor), não podemos esquecer que "além de ocupar o espaço escolar e buscar direcioná-lo em conformidade com os interesses de classe do proletariado, é preciso criar alternativas de educação para e pelo proletariado organizado".

Por isso, Paulo, em sua memória preservamos a esperança no papel da educação em contribuir para mediar o desenvolvimento dos indivíduos das massas trabalhadores para que se 
elevem à condição de classe dominante com o propósito coletivo e revolucionário de destruir as classes sociais, pois, enquanto existirem as classes, Paulo, entendemos que toda essa nossa luta, que foi a sua luta contra o conservadorismo, poderá continuar a ser mais doída.

Finalizamos, aqui, nossa carta-manifesto refirmando nossos compromissos revolucionários com a educação, o trabalho, a sociedade e a vida, de continuar lutando por uma terra sem amos e pela real igualdade, liberdade e universalização do gênero humano. Em homenagem à sua luta e aos trabalhadores que estão tombando pelas nossas causas, dedicamos a você e a todos eles uma parte da canção de Geraldo Vandré (1979) Réquiem para Matraga: "Vim aqui só pra dizer / Ninguém há de me calar / Se alguém tem que morrer / Que seja pra melhorar $[\ldots] "$.

Com luta, busca pelo conhecimento e com afeto, assinamos, nós.

\section{Referências}

ADRIÃO, T (2017). A privatização dos processos pedagógicos: grupos editoriais e os negócios na educação básica. In: MARIGONI, Gilberto (Org.) et al. O negócio da educação: aventuras na terra do capitalismo sem risco. São Paulo: Olho d'Água,.

ADRIÃO, T (2013). et al. A atuação de grupos empresariais em educação e sua inserção em redes públicas de ensino: reflexões iniciais. Políticas e gestão da educação: desafios em tempos de mudanças. São Paulo: Autores Associados. p. 267-283.

DIP, A (2018). Em nome de quem? A bancada evangélica e seu projeto de poder. 1. ed. Rio de Janeiro: Civilização Brasileira.

DUARTE, Newton (2020). "Um montão de amontoado de muita coisa escrita". Sobre o alvo oculto dos ataques obscurantistas ao currículo escolar. In: MALANCHEN, Julia; DE MATOS, Neide da Silveira Duarte; ORSO, Paulino José (org.). A pedagogia histórico-crítica, as políticas educacionais e a Base Nacional Comum Curricular. Campinas, SP: Editora Autores Associados.

FREIRE, P (1987). Pedagogia do Oprimido. 17. ed. Rio de Janeiro: Paz e Terra.

FREIRE, P. (2000). Pedagogia da indignação: cartas pedagógicas e outros escritos. São Paulo: Editora UNESP.

FRIGOTTO, G. (2011). Os circuitos da história e o balanço da educação no Brasil na primeira década do século Revista Brasileira de Educação. v. 16 n. 46 jan. |abr. Revista Educação \& Sociedade.

KORYBKO, A (2018). Guerras híbridas: das revoluções coloridas aos golpes. 1. ed. São Paulo: Expressão Popular. 
LÊNIN, VI. (1987). O Estado e a revolução: a doutrina marxista do Estado e as tarefas do proletariado na revolução. São Paulo: Global.

LEONTIEV, A. (1978). O desenvolvimento do psiquismo. Lisboa: Livros Horizonte.

MARTINS, LM. (2013). O desenvolvimento do psiquismo e a educação escolar: contribuições à luz da psicologia histórico-cultural e da pedagogia histórico-crítica. Campinas, SP: Autores Associados, 2013.

MARTINS, LM. (2018). O sofrimento e/ou adoecimento psíquico do(a) professor(a) em um contexto de fragilização da formação humana. Cadernos cemarx, $\mathrm{n}^{\circ} 11$.

MARX, K. (2011). A guerra civil na França. São Paulo: Boitempo.

MARX, K. (2011). O 18 brumário de Luís Bonaparte. São Paulo: Boitempo.

MARX, K. ENGELS, F. (2005). Manifesto Comunista. São Paulo: Boitempo.

MASCARO, A. L. (2013). Estado e forma política. São Paulo, SP: Boitempo.

MÉSZÁROS, I. (2004) O poder da ideologia. São Paulo: Boitempo.

MONTORO, X. A. (2018) Financeirização? Não, imperialismo, crescimento da exploração e crise crescente do capital. A Verdade: Revista teórica da $4^{a}$ internacional. Edição em Língua Portuguesa. n. 97, ago. ISSN 1679-2742.

MONTORO, X. A. (2016). Capitalismo y economía mundial. Madrid: Instituto Marxista de Economía - IME.

SAVIANI, D. (2013). Pedagogia histórico-crítica: primeiras aproximações. 11. ed. Campinas, SP: Autores Associados.

SAVIANI, D. (2008). História das idéias pedagógicas no Brasil. 2. ed. Campinas, SP: Autores Associados.

SAVIANI, D. (2010). Interlocuções pedagógicas: conversas com Paulo Freire e Adriano Nogueira e 30 entrevistas sobre educação. Campinas, SP: Autores Associados, 2010.

SOUZA, JJF. (2017). A Elite do Atraso. Da escravidão à Lava Jato. ed. Casa da Palavra/LeYa. Rio de Janeiro.

TROTSKY, L. (2007). A revolução permanente. 1. ed. São Paulo: Expressão Popular.

VIGOTSKI, L. S. (2009). A construção do pensamento e da linguagem. 2. ed. São Paulo: Editora WMF Martins Fontes, 2009.

VYGOTSKY, L. S. (2004). A transformação socialista do homem. Marxists Internet Archives, 2004. Disponível em:

https://www.marxists.org/portugues/vygotsky/1930/mes/transformacao.htm. 